\title{
Violence in older people with mental illness
}

\author{
Charlotte E. O'Callaghan, Anna V. Richman \& Biswadeep Majumdar
}

\begin{abstract}
SUMMARY
Aggression is common in older people with mental illness, with $15-43 \%$ of community referrals to old age psychiatry services and $44-65 \%$ of older people with Alzheimer's disease living in the community exhibiting such behaviour. In psychiatric in-patient units, assaults on staff are most common on wards for elderly people with organic mental illness. There is little high-quality research into the management of aggressive behaviour in dementia. We consider the available literature, which has shown certain behavioural measures and different classes of medication to be of benefit. We discuss factors associated with violence in elderly people with mental illness and potential management options.
\end{abstract}

\section{DECLARATION OF INTEREST}

None.

Violent behaviour is not usually perceived to be linked with older age, but the findings of the 2006-2007 National Audit of Violence contradict this view: members of staff working on wards for older people (generally over 65 years of age) with organic mental illness are more likely to be assaulted than in any other psychiatric in-patient area (Royal College of Psychiatrists' Centre for Quality Improvement 2008). Stress associated with violence in the workplace has been estimated to account for about $30 \%$ of the overall costs of ill health (Health and Safety Executive 2009), and aggression towards informal carers has been associated with an increased risk of elder abuse (Pillemar 1992).

Reviews of violence in psychiatric populations have revealed two clusters of higher-risk patients. The first is a younger group, either male or female, with a history of schizophrenia, substance misuse or personality disorder. The second is an older population, with a history of organic disorder or psychosis (Flannery 2005).

\section{What do we mean by violence?}

There is a lack of consensus in the literature on a strict definition of 'violence'. In the context of this article, we suggest the following description of work-related violence: 'any incident in which a person is abused, threatened or assaulted in circumstances relating to their work' (Health and Safety Executive 1996). Staff in care homes perceive both physical and verbal aggression in the workplace as violence (Gates 1999), and the terms violence and aggression are sometimes used interchangeably. Hall \& O'Connor (2004) note the difficulty of defining aggressive behaviour in patients with dementia 'as there is overlap between agitation, resistive behaviour and overt verbal and physical aggression'.

\section{Prevalence}

\section{Community and 24-hour care}

Studies of psychogeriatric services have found aggression to be an important part of the presentation in $15-43 \%$ of community-based referrals, with physical aggression being present in 50-69\% of these cases (Shah 1993; Gibbons 1997).

Community studies have observed aggression to be a common problem in people with dementia. The most frequently reported types of physical aggression are hitting, throwing, pushing (Ryden 1988) and grabbing (O'Leary 2005). When present in dementia, aggression has been demonstrated to be a persistent symptom. A study of patients with mild Alzheimer's disease found that of those who exhibited aggression, 70\% continued to do so after 2 years (Eustace 2002). Verbal aggression occurs more frequently than physical aggression, and aggression of any type is present in 44-65\% of community patients with Alzheimer's disease (Ryden 1988; Gormley 1998).

\section{In-patients}

Violent acts have been reported in $40 \%$ of psychogeriatric in-patients, the majority of whom were diagnosed with Alzheimer's dementia (Almvik 2006). The National Audit of Violence (Royal College of Psychiatrists' Centre for Quality Improvement 2008) provides an overview of violence on in-patient units (Box 1).

\section{What factors are associated with violence?}

From a behavioural perspective, violence has been described as either reactive or premeditated.
Charlotte E. O'Callaghan is a specialist registrar in old age psychiatry on the Mersey Rotational Training Scheme. Anna V. Richman is a consultant in old age psychiatry at Mossley Hill Hospital, Liverpool. Biswadeep Majumdar is also a consultant in old age psychiatry, at Waterloo Day Hospital, Liverpool. Correspondence Dr Biswadeep Majumdar, Waterloo Day Hospital, Park Road, Liverpool L22 3XR, UK. Email: deep.majumdar@merseycare. nhs.uk 
BOX 1 National Audit of Violence 2006-2007

An audit of violence on in-patient units in the UK carried out by the Healthcare Commission and the Royal College of Psychiatrists compared older people's services and working-age adult services:

- $64 \%$ of nurses working in older people's services had been physically assaulted on an in-patient unit, compared with $46 \%$ of nurses in adult services

- nurses in adult services were more likely to feel threatened or unsafe than those in older people's services and they were more likely to have a rehearsed response to emergency alarm calls

- rapid tranquillisation was used less often in older people's units than in adult units (48\% v. $66 \%)$

- there were similar levels of hands-on restraint, high-level observation and incident management in older people's and in adult units

- patient-on-patient assault was less common in older people's units: 6\% of patients had been subjected to physical assault in older people's units, compared with $18 \%$ of patients in adult units

- despite such high levels of violence, older people's units in some areas may be ill equipped to cope with such behaviour: the survey found inadequate training, alarm systems and ward layout, in addition to lack of activities and access to secure outdoor areas.

(Royal College of Psychiatrists' Centre for Quality Improvement 2008)

Reactive aggression is said to be subject to 'top-down' control from the orbitofrontal cortex and anterior cingulate cortex, modulating 'bottom-up drives' from the limbic regions. Premeditated aggression is associated with few signs of autonomic arousal (Siever 2008). Patients with functional or organic mental disorder may have more difficulty controlling aggressive impulses (this will be further explored below). A behavioural analysis may help to clarify which precursors are relevant for an individual patient: for reactive aggression, environmental factors are important and potentially modifiable.

\section{Environmental triggers}

Activities of daily living

Violence towards staff in community settings has been associated with assistance in carrying out activities of daily living in approximately twothirds of cases (Ware 1990). In studies conducted in in-patient units and nursing homes, refusal of services was the most frequent precipitant of assault by patients with functional and organic illnesses (Ticehurst 1992; Almvik 2006): having a bath or shower was thought to have precipitated nearly a fifth of assaults. Greater impairment in activities of daily living has been associated with increased risk of physical aggression towards staff in patients with Alzheimer's disease, even after adjusting for severity of dementia (Lyketsos 1999).
Milieu

Ward staff perceive excessive noise and lack of activities on the unit to contribute towards violence (Royal College of Psychiatrists' Centre for Quality Improvement 2008). The 2006 National Institute for Health and Clinical Excellence (NICE) guidelines for dementia note the following to be associated with violence and aggression: overcrowding, lack of privacy, lack of activities, inadequate staff attention, poor communication between staff and service user, conflicts between staff and carers, and weak clinical leadership.

\section{Communication}

In a study of 18 patients with Alzheimer's disease, Welsh et al (1996) found that aggression was correlated with the degree of language impairment. Problems with verbal communication were thought to precipitate $17 \%$ of aggressive episodes in a study of in-patients with organic or functional mental illnesses and nursing home residents (Almvik 2006).

\section{Biological causes}

\section{Structural abnormalities}

Neuroimaging, electroencephalogram (EEG) and post-mortem studies suggest that violent behaviour is associated with inferior frontal and medial temporal lobe dysfunction (Siegel 2007). Aggressive patients with dementia have been observed to have significantly reduced blood flow to the left anterior temporal, right parietal and bilateral dorsofrontal cortices (Hirono 2000).

Frontal and temporal slowing of the EEG has been observed in patients with schizophrenia with a history of violence (Hoptman 2003). Burns et al (1990) reported an association between temporal lobe atrophy and aggression in individuals with Alzheimer's disease. Kluver-Bucy syndrome (described following bilateral temporal lobectomy in monkeys) can include emotional changes, including 'rage' reactions and loss of fear, and has been described in patients with Alzheimer's disease and Pick's disease (Burns 1990).

\section{Neurochemical abnormalities}

Serotonin facilitates the prefrontal regions involved in the modulation of aggressive behaviour (Siever 2008). Levels of serotonin metabolites have been observed to be reduced in several studies of individuals with a history of aggression and impulsivity (Siever 2008). Deficits in serotonergic functioning have also been observed in Alzheimer's disease and have been correlated with aggressive behaviour (Mintzer 2001). 
Other neurotransmitters thought to be involved in the mediation of violent behaviour include noradrenaline, dopamine, cholecystokinin, glutamate, vasopressin, $\gamma$-aminobutyric acid and opioid peptides (Siever 2008).

\section{Gender}

The influence of gender on violence in elderly people is not clear. Community and in-patient studies in people with dementia appear to show no difference between genders, whereas studies in older people with functional mental illness seem to demonstrate that violence is more common in males (Aarsland 1996; Gormley 1998; Flannery 2005; O’Leary 2005).

In the general population, the male:female ratio for perpetrators of homicides is 9:1; in the over-65s this increases to 19:1 (Appleby 2006). Males greatly outnumbered females in a study of older people with mental illness who had attempted or carried out homicide (Ticehurst 1992).

\section{Premorbid level of functioning}

In patients with Alzheimer's disease, physical and non-physical aggression have been associated with a childhood history of conduct problems (O'Leary 2005). Prior level of education has been found not to predict aggressive behaviour (Aarsland 1996).

\section{History of violence}

Compared with the literature on younger adults, there is little discussion of history of violence in the literature on the elderly. In a community study of aggressive patients, the majority of whom had dementia, 22\% had a premorbid history of aggression (Gibbons 1997). Elderly people referred to forensic services tended to commit their first offence in middle age (Coid 2002).

\section{Personality}

In a community study of patients with dementia, aggressive behaviour was viewed as being very different from the premorbid personality in 39\% of patients, $58 \%$ demonstrated an exaggeration of premorbid personality, and in 3\% no difference was noted (Ware 1990).

In forensic settings, schizoid personality traits occur more frequently in elderly people, compared with a predominance of antisocial and borderline personality disorders in younger age groups (Coid 2002; Fazel 2002).

\section{Comorbid medical illness}

Explosive aggression has been associated with temporal lobe epilepsy, and it reduces following temporal lobectomy for epilepsy control, particularly in patients with mesial temporal lobe sclerosis. However, such features have typically been observed in younger patients. Aggressive epileptic automatisms (during or immediately after a seizure) start and stop abruptly, and the individual may appear confused during the episode; this contrasts with the gradual build up of anger and tension seen in a simple outburst of aggression. However, criminal violence of this nature is rare (Lishman 1998).

Stroke, brain tumours and closed-head injuries have all been associated with aggression, thought to be secondary to underlying dysfunction of the orbitofrontal and basotemporal cortices (Starkstein 1997). Delirium is common in older people, although it infrequently presents with aggression (Meagher 2001). In patients with communication difficulties, it is essential to consider pain, constipation, dental caries and skin rashes as potential causes of aggression (Hall 2004).

In an Australian study, just over a third of elderly psychiatric patients charged with attempted or actual homicide had comorbid physical illness, nearly half had significant hearing impairment and a fifth had significant impairment of vision (Ticehurst 1992).

Medications are a potential cause of aggression: Box 2 provides a (non-exhaustive) list.

\section{Psychiatric illness}

Flannery et al (2005) note the dearth of studies into assaultive behaviour by older people with mental illness. The 2006 National Confidential Inquiry into Suicides and Homicides by People with Mental Illness (Appleby 2006) revealed that perpetrators of homicide in England and Wales over the age of 65 are more likely than their younger counterparts to receive a verdict of diminished responsibility, or a hospital or community rehabilitation order. However, the report does not break down diagnoses by age group.

BOX 2 Medications reported to cause aggression

\begin{tabular}{lll}
\hline Antidepressants & Anticonvulsants & Cholinesterase inhibitors \\
- Escitalopram & - Sodium valproate & - Donepezil \\
- Sertraline & - Carbamazepine & - Galantamine \\
- Venlafaxine & - Ethosuximide & Other \\
- Reboxetine (not licensed & • Zonisamide & - Benzodiazepines \\
in the UK for people over & - Levetiracetam & - Melatonin \\
65 years of age) & - Vigabatrin & - Bupropion \\
& & - Montelukast \\
& & (British Medical Association 2010)
\end{tabular}


Psychotic illness

In a study of elderly patients referred to forensic psychiatric services, Lewis et al (2006) found that violent offences were strongly associated with paranoia at the time of the offence. Perhaps unsurprisingly, active symptoms at the time of the offence were more predictive of a violent offence than was a previous history of mental disorder.

In their study of elderly psychiatric patients who had attempted or committed homicide, Ticehurst et al (1992) found that nearly 50\% of homicides were thought to be precipitated by delusional beliefs, the most common being delusions of jealousy.

In patients with dementia, hallucinations and delusional beliefs have been significantly associated with episodes of aggression (Aarsland 1996; Gormley 1998). Between 25 and 40\% of cases of delusional misidentification may occur within the context of an organic disorder, with up to $30 \%$ of patients with Alzheimer's disease exhibiting this phenomenon. Other neuropsychiatric conditions where this has been observed include Lewy body dementia, multi-infarct dementia, head trauma, epilepsy, cerebrovascular disease and other intracerebral tumours and infective processes (Edelstyn 1999; Bourget 2004).

\section{Affective disorders}

Depression in people with dementia living in the community has been associated with increased risk of physical aggression (Lyketsos 1999), although not all studies have found this link (Aarsland 1996). Just over two-fifths of elderly people referred to medium and high secure forensic services have a diagnosis of depression (Coid 2002).

Aggression can be a symptom of mania, but there is little discussion of this in the literature in relation to violence by older people.

\section{Substance use}

Alcohol misuse is common in perpetrators of homicide: $50 \%$ of perpetrators of all age groups with a psychiatric report misuse alcohol, and $20 \%$ have a dependence syndrome (Appleby 2006). A study of elderly psychiatric patients who had attempted or committed homicide found that almost 50\% had a history of alcohol misuse (Ticehurst 1992). Another study of a non-forensic elderly psychiatric in-patient population found that $74 \%$ of patients who had behaved aggressively towards staff had a history of substance misuse (Flannery 2005).

\section{Dementia}

As mentioned earlier, in psychiatric in-patient units in England and Wales, the highest rates of violence occur on wards for elderly people with organic mental illness, where $73 \%$ of nursing staff have been the victim of assault from a patient (Royal College of Psychiatrists' Centre for Quality Improvement 2008).

Aggression and agitation can occur as part of a broader spectrum of behavioural and psychological symptoms in dementia (BPSD). These symptoms have been clustered into three main types: agitation, psychosis and mood disorder (Box 3). Such symptoms are common, affecting up to $90 \%$ of people at some point in their illness (Ballard 2006). Physical aggression in patients with Alzheimer's disease has been positively correlated with agitation (O'Leary 2005). Aggression is equally likely in Alzheimer's disease and vascular dementia (Lyketsos 2000; O'Leary 2005) and some, but not all, studies have found that its prevalence increases with the severity of these illnesses (Gormley 1998; Eustace 2002; Hall 2004).

Behavioural symptoms typically occur earlier in the course of frontotemporal dementia than in Alzheimer's disease (Harciarek 2005).

An Australian study of 14 elderly psychiatric patients who attempted or committed homicide found cognitive impairment to be present in almost all of the group, with just over half having a diagnosis of dementia (Ticehurst 1992). Fazel et al (2002) note that dementia may be underrepresented in the sex-offender population: people with dementia may be diverted from the criminal justice system or their actions may not be perceived as an offence.

BOX 3 Behavioural and psychological symptoms of dementia
Agitation
- Aggression
- Irritability
- Restlessness
- Shouting
- Pacing
Psychosis
- Visual hallucinations
- Auditory hallucinations
- Persecutory delusions
Altered mood
- Depression
- Anxiety
- Apathy

(Ballard 2006) 


\section{Who are the potential victims?}

In the community, carers of people with dementia are frequently exposed to aggression. Ryden (1988) observed that $65 \%$ of carers/family members were subjected to aggression, which occurred daily in $16 \%$ of cases.

The National Audit of Violence (Royal College of Psychiatrists' Centre for Quality Improvement 2008) has demonstrated that nursing staff are more likely to be the victims of assaultive behaviour on in-patient units than are other clinical or nonclinical staff (64\% v. 20\% v. 23\%). Other studies have observed assaults to occur most frequently during the day shift (Astrom 2002; Flannery 2005).

Staff victims of assault have been observed to be younger and less experienced or with anxiety traits or an external locus of control (Ray 1998; Astrom 2002).

Appleby et al (2006) observed that, among perpetrators of homicide, those with a mental illness are more likely than their mentally well counterparts to murder a family member, spouse or former spouse than an acquaintance or stranger. Studies among older populations support this finding (Ticehurst 1992).

\section{Consequences of violence}

Most studies show that despite the high levels of violence on psychogeriatric units, rates of physical injury to staff are low, with one study finding that nearly half of all assaults on staff did not cause any lasting consequence to the victim and only $1 \%$ required treatment (Almvik2006). Violentincidents are often reported only if medical attention has been required (Gates 1999). Nurses may normalise violence from older patients, seeing the behaviour to be a result of confusion and sometimes viewing it as more acceptable than aggression perpetrated by a younger adult or someone who is intoxicated (Akerstrom 2002).

Aggression can lead to increased carer burden and placement in care homes (Shah 1993), or psychiatric in-patient admission (Gibbons 1997). Even where violence is verbal, not physical, it causes distress to carers and is associated with deterioration in the relationship between the carer and the patient (Ware 1990). It may contribute to the risk of elder abuse (Pillemer 1992).

\section{Management}

It is beyond the scope of this article to discuss the management of all of the conditions described. We therefore focus on the management of aggressive behaviour in patients with dementia, which often
BOX 4 Case vignette: non-pharmacological and pharmacological interventions for violence

A 75-year-old man with vascular dementia and harmful use of alcohol was living at home with his elderly wife and had no other support. When referred by his general practitioner (GP), he had been physically aggressive towards his wife only and she was struggling to cope. The GP had started him on a low dose of quetiapine, which had provided some reduction in aggression, although adherence was erratic. His wife was giving him alcohol in the evenings as he was demanding it and he would become aggressive if it was withheld.

When seen at home, there was evidence of extrapyramidal side-effects: his mobility was poor and he struggled to maintain an upright sitting posture at times. His wife was clearly struggling with the home situation, although was reluctant to admit it and wanted her husband to be treated at home.

A community nurse became involved, providing education and support to the wife. The nurse began a behavioural analysis to facilitate a behavioural management programme. Attendance at the local day centre was arranged via Social Services, with a daily care package to monitor medication. A regime for gradually reducing alcohol intake was started. Quetiapine was immediately reduced and stopped and the side-effects improved, but aggression resurfaced. A low dose of trazodone was commenced. Some verbal aggression remained, but the physical aggression abated with this management, thus improving the home situation. After 3 months, trazodone was withdrawn and stopped and the situation remained manageable.

involves a combination of non-pharmacological and pharmacological interventions. The fictitious case vignette in Box 4 illustrates such an approach.

\section{Non-pharmacological management}

The general principles of managing violent or aggressive behaviour are also applicable in dementia. ${ }^{\dagger}$ Hence, staff should be trained in deescalation techniques and use of physical restraint (National Institute for Health and Clinical Excellence 2005). Seclusion should be used only as a last resort 'to contain severely disturbed behaviour which is likely to cause harm to others' (Department of Health 2008).

Three systematic reviews on this topic (CohenMansfield 2001; Livingston 2005; Verkaik 2005) reveal that various techniques addressing behavioural management, environmental manipulation and psychosocial functioning have produced some reduction in aggression/agitation (Box 5). Livingston et al (2005) observed that staff education and behavioural management techniques tailored to the individual patient appeared the most effective in achieving sustained improvement in BPSD. The reviewers note the poor quality of research in this area and highlight that more rigorous studies are required before conclusive recommendations can be made.

Aromatherapy has been demonstrated to reduce agitation in patients with severe dementia. Ballard et al (2002) used melissa oil (lemon balm), which was combined with a skin lotion and applied to

\author{
For a discussion of management \\ techniques in Advances see: \\ Davison SE (2005) The management \\ of violence in general psychiatry. 11 : \\ 362-70; Macpherson R, Dix R, \\ Morgan S (2005) A growing \\ evidence base for management \\ guidelines. 11: 404-15. Ed.
}


B0X 5 Non-pharmacological management

\begin{tabular}{ll}
\hline $\begin{array}{l}\text { Behavioural management techniques } \\
\text { - Social skills traininga }\end{array}$ & $\begin{array}{c}\text { - Escorting of individuals to outdoor garden, } \\
\text { allowing patient free access to outside }\end{array}$ \\
$\begin{array}{l}\text { - Functional analysis and identification of } \\
\text { abnormal behaviour }\end{array}$ & $\begin{array}{l}\text { - Removal of restraints } \\
\text { Improving psychosocial functioning }\end{array}$ \\
$\begin{array}{l}\text { - Bathing routines based on the personal } \\
\text { preference of the individual }\end{array}$ & $\begin{array}{l}\text { - Psychomotor therapy groups: sporting } \\
\text { activities and games to stimulate }\end{array}$ \\
- Staff education and training, including & cognition and psychosocial functioning \\
a manual-guided course for nursing & provided a small benefit on aggressive \\
assistants & behaviours in nursing home residents with \\
Environmental manipulation & Alzheimer's disease \\
- Group living (specially designed nursing & - Companion animals to reduce verbal \\
homes with a home-like atmosphere) & aggression \\
& a. Data from randomised controlled trials.
\end{tabular}

patients twice a day in a randomised placebocontrolled trial.

A recent independent report commissioned and funded by the Department of Health recommends increased education for care home staff, support for carers in identifying behavioural problems and employing behavioural management strategies, and the development of specialist mental health in-reach services for care homes to reduce pharmacological interventions for BPSD (Banerjee 2009).

\section{Pharmacological management}

The National Institute for Health and Clinical Excellence (2005) has published guidelines on the management of violence in an acute setting and its general guidance on rapid tranquillisation is summarised in Box 6. The NICE dementia guidelines advise that drug treatment for aggression in dementia should aim to calm the individual, 'rather than treat any underlying psychiatric condition' (National Institute for Health and Clinical Excellence 2006).

\section{Antipsychotics}

Atypical antipsychotics are the most commonly used drugs for aggression in dementia, but a report for the Department of Health advocates reduction in prescription of these drugs by twothirds over the next 2 years. It recommends that antipsychotics 'should not be a first-line treatment except in circumstances of extreme risk and harm' (Banerjee 2009), owing to concerns about the safety of these drugs.

In 2004, the Committee on Safety of Medicines issued guidance that risperidone and olanzapine conferred approximately a threefold increased risk of stroke in people with dementia. Following subsequent meta-analyses, it would appear that this may be a class effect for the atypicals (Banerjee 2009). The increased risk of stroke seems to be greatest within the first 2-3 months of treatment, with an overall pooled relative risk of stroke of 2.57. Individuals with dementia prescribed atypicals also have an increase in all-cause mortality, the pooled relative risk being 1.41. This risk 'persists for at least six months after initial prescription' (Banerjee 2009). Observational studies suggest even higher mortality among those prescribed typicals, although this may in part be due to prescription of haloperidol in delirium (Banerjee 2009).

In addition, there is evidence to suggest that antipsychotics may hasten cognitive decline (Ballard 2006) and most antipsychotics are

BOX 6 Summary of NICE (2005) guidelines for the administration of rapid tranquillisation

- Where de-escalation techniques have failed, rapid tranquillisation may be required

- Offer oral medication before administering intramuscular medication, unless this is not a proportionate response

- Where the patient is psychotic, use a combination of lorazepam and an antipsychotic (either haloperidol or olanzapine)

- Where there is no psychosis, use lorazepam alone

- Intramuscular lorazepam should not be given within $1 \mathrm{~h}$ of intramuscular olanzapine

- If using intramuscular haloperidol, give procyclidine or benzatropine in accordance with the manufacturer's instructions
- Use lower doses of medication for: older people those on other medications those with medical comorbidities (e.g. renal, hepatic, cardiovascular or neurological conditions

- Intramuscular diazepam, depot antipsychotics, and oral or intramuscular chlorpromazine or thioridazine are not recommended for rapid tranquillisation

- For patients with dementia: risperidone and olanzapine are not recommended

where intramuscular medication is required, a single agent is preferred (National Institute for Health and Clinical Excellence 2006) if a combination is required, use lorazepam and haloperidol monitor for deterioration of cognitive function

- If violence occurs over an extended time, zuclopenthixol acetate is an option, but only in patients previously exposed to antipsychotics

- Intravenous rapid tranquillisation: decision to be confirmed by a senior clinician should only be used where staff are trained in intermediate life support

monitor for respiratory depression, dystonia and cardiovascular compromise

- Following rapid tranquillisation, make regular observations of the patient's pulse, respiratory rate, temperature and blood pressure; a crash bag should be available within $3 \mathrm{~min}$ 
known to prolong the QTc interval to varying degrees (Ballard 2009). To minimise the risk of extrapyramidal side-effects, it is recommended that where antipsychotics are required, atypicals should be prescribed at the lowest possible dose, for less than 12 weeks (Banerjee 2009). Particular caution is required in patients with dementia with Lewy bodies: approximately half of those treated with antipsychotics may experience severe drug sensitivity (e.g. extrapyramidal symptoms, autonomic instability and falls), with evidence suggesting that olanzapine produces the highest frequency of serious sensitivity reactions in this group (Ballard 2006).

Ballard \& Howard (2006) have extensively reviewed antipsychotics in dementia. The strongest evidence for efficacy was for risperidone, which has five published randomised controlled trials (RCTs) and is now licensed for the short-term treatment (up to 6 weeks) of persistent aggression in moderate to severe Alzheimer's dementia unresponsive to non-pharmacological interventions and when there is a risk of harm to self or others' (British Medical Association 2010). The $1 \mathrm{mg} /$ day dose was associated with a significant effect on aggression, with more benefit and side-effects observed at $2 \mathrm{mg} /$ day. Three studies of olanzapine demonstrated a reduction in agitation and aggression at doses of $5-10 \mathrm{mg} /$ day; the overall effect of this drug was intermediate between risperidone and haloperidol. Four studies of haloperidol found a significant improvement in aggression, but not in agitation. One study of aripiprazole demonstrated significant improvements in agitation. A placebocontrolled study of quetiapine found no benefit on agitation. Many of the studies involved a mix of individuals with Alzheimer's or vascular dementia. None of the placebo-controlled studies reviewed involved people with frontotemporal dementia (Ballard 2006).

When antipsychotics were withdrawn from people with Alzheimer's disease as part of an $\mathrm{RCT}$, there was a non-significant trend for those with Neuropsychiatric Inventory (NPI) scores of 15 or over to benefit from continuation of an antipsychotic, whereas those with lower NPI scores did not experience any deterioration (Ballard 2008).

Benperidol is licensed for the 'control of deviant antisocial sexual behaviour' (British Medical Association 2010) and may be used for sexual disinhibition in dementia.

\section{Antidepressants}

Trazodone, fluoxetine, sertraline and citalopram have been assessed in placebo-controlled studies of the treatment of BPSD in community and inpatient settings. Citalopram (administered at a dose of $20 \mathrm{mg} /$ day) proved effective in reducing symptoms of agitation and lability, and sertraline was effective in the treatment of depression; no benefit seen for the other drugs in RCTs (Sink 2005). A head-to-head study showed trazodone to be as effective as haloperidol for reducing agitation, with fewer side-effects (Sultzer 1997).

\section{Mood stabilisers}

Carbamazepine has been demonstrated to reduce agitation in a number of small placebo-controlled studies (Ballard 2006). This drug is potentially difficult to use in elderly people, owing to the potential for drug interactions and haematological toxicity (Sink 2005).

A Cochrane review of sodium valproate in the management of agitation in dementia did not recommend its use for this indication. The RCTs reviewed were observed to be methodologically flawed and demonstrated lack of effect at lower doses (480 mg/day) with 'prohibitively increased frequency of adverse effects' at higher doses of 1000 mg/day (Lonergan 2009).

Both carbamazepine and sodium valproate have been associated with significantly lower mortality rates than olanzapine (Hollis 2007).

Sink et al (2005) note that there are no RCTs studying the effects of lithium in managing BPSD.

\section{Cholinesterase inhibitors}

There is some preliminary evidence to suggest that memantine may be of benefit in reducing agitation and aggression in Alzheimer's disease. Randomised controlled trials which should provide clarification are ongoing in the UK and Canada (Ballard 2009).

In Alzheimer's disease, NICE found 'moderate quality evidence' that donepezil reduces agitation and aggression (National Institute for Health and Clinical Excellence, 2006).

Galantamine has been demonstrated to significantly reduce agitation in a post hoc analysis of an RCT involving patients with Alzheimer's disease (Cummings 2004).

In one open-label study involving patients with Alzheimer's disease, rivastigmine was observed to significantly reduce agitation, although a second open-label study and an RCT have not replicated this finding (Figiel 2008). An RCT involving patients with dementia with Lewy bodies found that those with agitation and/or aggression neither worsened nor improved on rivastigmine (McKeith 2000). 


\section{Benzodiazepines}

Lorazepam has been studied in the acute management of agitation in dementia, an RCT demonstrating improvement in levels of agitation (Meehan 2002). Long-term treatment with benzodiazepines would not be advocated because of the increased risk of falls, the risk of paradoxical agitation and potential for dependence (Sink 2005).

\section{Hormones}

Case reports indicate that medroxyprogesterone acetate and cyproterone acetate have both been successfully used to manage disinhibited sexual behaviour in elderly men with dementia. Both may exacerbate depression and are contraindicated in patients with a history of thromboembolic disorders (Haddad 1993).

\section{Other}

Beta-blockers have been demonstrated to reduce aggressive behaviour. However, the studies have used high dosages and have been of small and heterogeneous groups (Stoppe 1999).

\section{Conclusions}

Aggressive behaviour is common in older people with mental illness, although the evidence suggests that it rarely results in significant injury to others. Such behaviour must be carefully assessed (Box 7) and consideration given to its impact on caregivers. The literature regarding management remains inconclusive, but we believe that with staff education, better access to psychological therapies

BOX 7 Assessment and management of violence and aggression in older people with mental illness

- Evidence of current mental illness or cognitive impairment

- Medical and psychiatric history, including use of alcohol and illicit substances

- History of violence; use of weapons (past/ present)

- Physical examination: assess for focal neurological deficit, evidence of infection, respiratory or cardiac failure, potential source of pain (e.g. dental caries, faecal impaction, urinary retention, injuries)

if the patient is too aggressive to examine, simple observation should note any gross neurological deficit, respiratory distress, pain or diaphoresis
- Investigations: consider full blood count, urea and electrolytes, bone profile, glucose, inflammatory markers, chest radiography, urinalysis, electrocardiogram, electroencephalogram and brain imaging

- Behavioural analysis (antecedents, behaviour, consequence)

- Medication review: consider stopping medication that may cause aggression

- Treat any medical or psychiatric disorder

- Ensure patient has sufficient analgesia

- Rectify hearing and vision impairments

- Psychosocial management where appropriate

- Consider use of medication, preferably combined with psychosocial interventions and the advent of nursing-home liaison teams, non-pharmacological management is a realistic intervention for many patients. Nevertheless, medication will continue to play a role for the more challenging patients.

\section{References}

Aarsland D, Cummings J, Yenner G, et al (1996) Relationship of aggressive behavior to other neuropsychiatric symptoms in patients with Alzheimer's disease. American Journal of Psychiatry 153: 243-7.

Akerstrom M (2002) Slaps, punches, pinches - but not violence: boundary-work in nursing homes for the elderly. Symbolic Interaction 25: $515-36$

Almvik R, Rasmussen K. Woods P (2006) Challenging behaviour in the elderly - monitoring violent incidents. International Journal of Geriatric Psychiatry 21: 368-74.

Appleby L, Shaw J, Kapur N, et al (2006) Five Year Report of the National Confidential Inquiry into Suicide and Homicide by People with Mental IIIness. The University of Manchester.

Astrom S, Bucht G, Eiseman M, et al (2002) Incidence of violence towards staff caring for the elderly. Scandinavian Journal of Caring Sciences 16: 66-72.

Ballard CG, O'Brien JT, Reichelt K, et al (2002) Aromatherapy as a safe and effective treatment for the management of agitation in severe dementia: the results of a double-blind, placebo-controlled trial with Melissa. Journal of Clinical Psychiatry 63: 553-8.

Ballard C, Howard R (2006) Neuroleptic drugs in dementia: benefits and harm. Nature Reviews Neurosciences 7: 492-500.

Ballard C, Lana MM, Theodoulou M, et al (2008) A randomised, blinded, placebo-controlled trial in dementia patients continuing or stopping neuroleptics (the DART-AD trial). PLoS Medicine 5: e76.

Ballard CG, Gauthier S, Cummings JL, et al (2009) Management of agitation and aggression associated with Alzheimer disease. Nature Reviews Neurology 5: 245-55

Banerjee S (2009) The Use of Antipsychotic Medication for People with Dementia: Time for Action. A Report for the Minister of State for Care Services. Department of Health.

Bourget D, Whitehurst L (2004) Capgras syndrome: a review of the neurophysiological correlates and presenting clinical features in cases involving violence. Canadian Journal of Psychiatry 49: 719-25.

British Medical Association, Royal Pharmaceutical Society of Great Britain (2010) British National Formulary 59. March 2010. BMJ Group \& RPS Publishing.

Burns A, Jacoby R, Levy R (1990) Psychiatric phenomena in Alzheimer's disease. IV: Disorders of behaviour. British Journal of Psychiatry 157 . $86-94$

Cohen-Mansfield J (2001) Nonpharmacological interventions for inappropriate behaviors in dementia. American Journal of Geriatric Psychiatry 9: 361-81.

Coid J, Fazel S, Kahtan N (2002) Elderly patients admitted to secure forensic psychiatry services. Journal of Forensic Psychiatry 13: 41627

Committee on Safety of Medicines (2004) Atypical Antipsychotic Drugs and Stroke. CSM (http://www.mhra.gov.uk/home/groups/pl-p/ documents/websiteresources/con019488.pdf).

Cummings J, Schneider L, Tariot P (2004) Reduction of behavioural disturbances and caregiver distress by Galantamine in patients with Alzheimer's disease. American Journal of Psychiatry 161: 532-8.

Department of Health (2008) Code of Practice: Mental Health Act 1983. TSO (The Stationery Office) 
Edelstyn NMJ, Oyebode $F$ (1999) A review of the phenomenology and cognitive neuropsychological origins of the Capgras syndrome. International Journal of Geriatric Psychiatry 14: 48-59.

Eustace A, Coen R, Walsh C, et al (2002) A longitudinal evaluation of behavioural and psychological symptoms of probable Alzheimer's disease. International Journal of Geriatric Psychiatry 17: 968-73.

Fazel S, Hope T, O'Donnell I, et al (2002) Psychiatric, demographic and personality characteristics of elderly sex offenders. Psychological Medicine 32: 219-26.

Figiel G, Sadowsky C (2008) A systematic review of the effectiveness of Rivastigmine for the treatment of behavioural disturbances in dementia and other neurological disorder. Current Medical Research and Opinion 24: 157-66.

Flannery R, Peterson M, Walker B (2005) Precipitants of elderly psychiatric patient assaults on staff: preliminary empirical enquiry. Psychiatric Quarterly 76: 167-75.

Gates D, Fitzwater E, Meyer U (1999) Violence against caregivers in nursing homes: expected, tolerated and accepted. Journal of Gerontological Nursing 25: 12-22.

Gibbons P, Gannon M, Wrigley M (1997) A study of aggression among referrals to a community-based psychiatry of old age service. International Journal of Geriatric Psychiatry 12: 384-8.

Gormley N, Rizwan MR, Lovestone S (1998) Clinical predictors of aggressive behaviour in Alzheimer's disease. International Journal of Geriatric Psychiatry 13: 109-15.

Haddad P, Benbow S (1993) Sexual problems associated with dementia: Part 2. Aetiology, assessment and treatment. International Journal of Geriatric Psychiatry 8: 631-7.

Hall K, O'Connor D (2004) Correlates of aggressive behaviour in dementia. International Psychogeriatrics 16: 141-58.

Harciarek M, Jodzio K (2005) Neuropsychological differences between frontotemporal dementia and Alzheimer's disease: a review. Neuropsychology Review 15: 131-45.

Health and Safety Executive (1996) Violence at Work: A Guide for Employers. HSE (http://www.hse.gov.uk/pubns/indg69.pdf).

Health and Safety Executive (2009) Workplace violence. HSE (http:// www.hse.gov.uk/healthservices/violence/index.htm).

Hirono N, Mega MS, Dinov I, et al (2000) Left frontotemporal hypoperfusion is associated with aggression in patients with dementia. Archives of Neurology 57: 861-6.

Hollis J, Grayson D, Forrester L, et al (2007) Antipsychotic medication dispensing and risk of death in veterans and war widows 65 years and older. American Journal of Geriatric Psychiatry 15: 932-41.

Hoptman MJ (2003) Neuroimaging studies of violence and antisocial behaviour. Journal of Psychiatric Practice 9: 265-78.

Lewis C, Fields C, Rainey E (2006) A study of geriatric forensic evaluees: who are the violent elderly? Journal of the American Academy of Psychiatry and the Law 64: 324-32.

Lishman WA (1998) Organic Psychiatry: The Psychological Consequences of Cerebral Disorder (3rd edn). Blackwell Science.

Livingston G, Johnston K, Katona C, et al (2005) Systematic review of psychosocial approaches to the management of neuropsychiatric symptoms of dementia. American Journal of Psychiatry 162: 19962021.

Lonergan ET, Luxenberg J (2009) Valproate preparations for agitation in dementia. Cochrane Database of Systematic Reviews issue 3: CD003945.

Lyketsos C, Steele C, Galik E, et al (1999) Physical aggression in dementia patients and its relationship to depression. American Journal of Psychiatry 156: 66-71.

Lyketsos C, Steinberg M, Tschanz J, et al (2000) Mental and behavioral disturbances in dementia: findings from the Cache County Study on Memory and Aging. American Journal of Psychiatry 157: 708-14.
McKeith IG, Del Ser T, Spano PF, et al (2000) Efficacy of rivastigmine in dementia with Lewy bodies: a randomised, double-blind, placebocontrolled international study. Lancet 356: 2031-6.

Meagher D (2001) Delirium: optimising management. BMJ 322: 144-9.

Meehan KM, Wang H, David S (2002) Comparison of rapidly acting intramuscular olanzapine, lorazepam, and placebo: a double-blind, randomized study in acutely agitated patients with dementia. Neuropsychopharmacology 26: 494-504

Mintzer J (2001) Underlying mechanisms of psychosis and aggression in patients with Alzheimer's disease. Journal of Clinical Psychiatry 62: $23-5$.

National Institute for Health and Clinical Excellence (2005) Violence. The Short-Term Management of Disturbed/Violent Behaviour in Psychiatric In-patient Settings and Emergency Departments (Clinical Guideline CG25). Royal College of Nursing

National Institute for Health and Clinical Excellence (2006) Dementia. A NICE-SCIE Guideline on Supporting People with Dementia and their Carers in Health and Social Care (Clinical Guideline CG42). The British Psychological Society \& Gaskell.

O'Leary D, Jyringi D, Sedler M (2005) Childhood conduct problems, stages of Alzheimer's disease, and physical aggression against caregivers. International Journal of Geriatric Psychiatry 20: 401-5.

Pillemer K, Suitor J (1992) Violence and violent feelings: what causes them among family caregivers? Journals of Gerontology 24: \$165-72.

Ray C, Subich L (1998) Staff assaults and injuries in a psychiatric hospital as a function of three attitudinal variables. Issues in Mental Health Nursing 19: 277-89.

Royal College of Psychiatrists' Centre for Quality Improvement (2008) The Healthcare Commission National Audit of Violence 2006-7. Final Report - Older People's Services. Royal College of Psychiatrists.

Ryden M (1988) Aggressive behaviour in persons with dementia who live in the community. Alzheimer Disease and Associated Disorders 2 : $342-55$

Shah A (1993) Aggressive behaviour among patients referred to a psychogeriatric service. Medicine, Science, and the Law 33: 144-50.

Siegel A, Bhatt S, Bhatt R, et al (2007) The neurological basis for the development of pharmacological treatments of aggressive disorders. Current Neuropharmacology 5: 135-47.

Siever L (2008) Neurobiology of aggression and violence. American Journal of Psychiatry 165: 429-42.

Sink KM, Holden KF, Yaffe K (2005) Pharmacological treatment of neuropsychiatric symptoms of dementia: a review of the evidence. Journal of the American Medical Association 293: 596-608.

Starkstein S, Robinson R (1997) Mechanism of disinhibition after brain lesions. Journal of Nervous and Mental Disease 185: 108-14.

Stoppe G, Brandt CA, Staedt JH (1999) Behavioural problems associated with dementia. The role of newer antipsychotics. Drugs \& Aging 14: 41-54

Sultzer DL, Gray KF, Gunay I, et al (1997) A double-blind comparison of trazodone and haloperidol for treatment of agitation in patients with dementia. American Journal of Geriatric Psychiatry 5: 60-9.

Ticehurst S, Ryan M, Hughes F (1992) Homicidal behaviour in elderly patients admitted to a psychiatric hospital. Dementia 3: 86-90.

Verkaik R, van Weert JCM, Francke AL (2005) The effects of psychosocial methods on depressed, aggressive and apathetic behaviours of people with dementia: a systematic review. International Journal of Geriatric Psychiatry 20: 301-14.

Ware CJG, Fairburn CG, Hope RA (1990) A community-based study of aggressive behaviour in dementia. International Journal of Geriatric Psychiatry 5: 337-42.

Welsh S, Corrigan F, Scott M (1996) Language impairment and aggression in Alzheimer's disease. International Journal of Geriatric Psychiatry 11: 257-61.
MCO answers

$1 d \quad 2$ e 3 a $\quad 4$ e 5 b 


\section{MCQs}

Select the single best option for each question stem

1 Studies of violence by older people have shown that:

a it is more common in males

b in the general population, female perpetrators of homicide greatly outnumber male perpetrators

c level of education predicts aggressive behaviour

d in forensic settings, schizoid personality traits occur more frequently

e perpetrators of homicide over the age of 65 are as likely to receive a verdict of diminished responsibility as their younger counterparts.

2 Aggression in Alzheimer's disease:

a has not been linked with depression

$\mathrm{b}$ is uncommon towards the main carer

c usually does not persist beyond 2 years of illness

d occurs more frequently than in vascular dementia

e has been linked with greater severity of impairment of activities of daily living.
3 Studies of structural and neurochemical abnormalities have shown that:

a violent behaviour is associated with frontal and temporal lobe dysfunction

$\mathrm{b}$ in aggressive patients with dementia, there is significant increase in blood flow to the left anterior temporal and right parietal lobes

c aggression in Alzheimer's disease is associated with high levels of cortical serotonin

d dopamine appears to offer the most persuasive evidence in terms of a role in aggression

e frontal and temporal slowing of the electroencephalogram is not observed in patients with schizophrenia with a history of violence.

4 Studies of non-pharmacological management have shown that:

a group-living situations do not provide any benefit

b escorting patients to outdoor gardens and giving free access does not provide any benefit

c removal of restraints usually makes aggression worse

d alteration of design of corridors in nursing homes appears to be the most effective in sustained improvement in behavioural and psychological symptoms in dementia (BPSD)

e staff education and behavioural management techniques appears to be the most effective in sustained improvement in BPSD.

\section{Studies of pharmacological management} have shown:

a haloperidol to have a greater effect size than risperidone in reducing symptoms of aggression

b increased mortality rates in patients with Alzheimer's disease taking atypical antipsychotics compared with those not taking them

c haloperidol to result in substantial improvements in aggression

d lithium to be more effective than haloperidol in reducing aggression

e both carbamazepine and sodium valproate to be associated with significantly higher mortality rates than olanzapine. 